\title{
Oxidized Low-Density Lipoprotein-Induced Cyclophilin A Secretion Requires ROCK-Dependent Diphosphorylation of Myosin Light Chain
}

\author{
Zizhuo Su Rongjie Lin Yuyang Chen Xiaorong Shu Haifeng Zhang \\ Shumin Liang Ruqiong Nie Jingfeng Wang Shuanglun Xie
}

Department of Cardiology, Sun Yat-Sen Memorial Hospital, Sun Yat-Sen University, and Guangdong Province

Key Laboratory of Arrhythmia and Electrophysiology, Guangzhou, China

\section{Key Words}

Oxidized low-density lipoprotein · Cyclophilin A · Myosin

light chain - Actin remodeling

\begin{abstract}
Objective: Accumulation of cyclophilin A (CyPA) within atherosclerotic lesions is thought to be implicated in the progression of atherosclerosis. However, the source of CyPA within atherosclerotic lesions is still unknown. The aim of this study is to determine the role of oxidized low-density lipoproteins (ox-LDL) in vascular smooth muscle cell (VSMC)derived CyPA secretion and the underlying mechanism. Methods and Results: Abundant CyPA and a-smooth muscle actin (a-SMA) expressed in atherosclerotic lesions was observed in apolipoprotein E-deficient mice. ox-LDL induced CyPA secretion from a primary culture of rat aortic smooth muscle cells in a dose- and time-dependent manner. Sulfosuccinimidyloleate, a CD36 inhibitor, prevented the oxLDL-induced CyPA secretion. Pre-exposure to either the actin-depolymerizing agent cytochalasin D or the actin-polymerizing agent jasplakinolide inhibited CyPA secretion induced by ox-LDL. Gene silencing of vesicle-associated membrane protein 2 suppressed ox-LDL-induced CyPA se-
\end{abstract}

cretion. ox-LDL caused the phosphorylation of myosin light chain (MLC). Inhibition of MLC by blebbistatin reversed the secretion of CyPA and the phosphorylation of MLC induced by ox-LDL. MLC kinase inhibitor ML-7 reduced the monophosphorylation of MLC but did not reduce CyPA secretion. Pretreatment with the rho-associated coiled-coil kinase (ROCK) inhibitor Y27632 blocked diphosphorylation of MLC and secretion of CyPA induced by ox-LDL. Conclusions: oxLDL-induced CyPA secretion requires vesicle transportation, actin remodeling and $\mathrm{ROCK}$-dependent diphosphorylation of MLC. VSMC-derived CyPA induced by ox-LDL may be associated with increased CyPA expression in atherosclerotic lesions.

๑) 2016 S. Karger AG, Basel

\section{Introduction}

Atherosclerosis (AS) is a leading cause of disability and death worldwide. Multiple lines of evidence suggest that AS is a chronic inflammatory disease causing atherosclerotic plaque formation and luminal stenosis of the arteries.

Z.S. and R.L. contributed equally to this paper.

\section{KARGER}

E-Mail karger@karger.com

www.karger.com/jvr (c) 2016 S. Karger AG, Basel

$1018-1172 / 16 / 0534-0206 \$ 39.50 / 0$
Dr. Jingfeng Wang or Dr. Shuanglun Xie

Department of Cardiology, Sun Yat-Sen Memorial Hospital, Sun Yat-Sen University No. 107, West Yanjiang Road

Guangzhou 510120 (China)

E-Maildrwjf@sina.com or xieshuanglun@sina.com 
Cyclophilin A (CyPA), a proinflammatory factor, is ubiquitously distributed in all prokaryotes and eukaryotes. CyPA is involved in the pathophysiology of various cardiovascular diseases, including AS [1], abdominal aortic aneurysm [2], and myocardial infarction [3]. It is abundantly expressed in atherosclerotic lesions [4, 5]. Either knockout or knockdown of CyPA expression mitigates the progression of AS in apolipoprotein Edeficient $\left(\right.$ apoE $\left.^{-/-}\right)$mice $[1,6]$. However, the source of the $\mathrm{CyPA}$ present in atherosclerotic plaque remains unclear. It has been shown that bone marrow-derived CyPA does not play a significant role in AS formation [1] and that CyPA derived from vascular smooth muscle cells (VSMC) plays a vital role in vascular remodeling $[2,7]$. Therefore, we speculated that VSMC could be an important source of CyPA in atherosclerotic lesions.

Oxidized low-density lipoprotein (ox-LDL) promotes intracellular production of reactive oxygen species (ROS) in VSMC [8-10]. Previous studies have shown that ROS can induce CyPA secretion from rat aortic smooth muscle cells (RASMC) through signaling pathways involving vesicle transportation, actin remodeling, and myosin II activity $[11,12]$. However, the potential role of ox-LDL in VSMC-derived CyPA secretion remains elusive. This study was designed to explore this role and the underlying mechanism.

\section{Materials and Methods}

\section{Antibodies and Chemicals}

Mouse anti-actin (ab3280), rabbit anti-CyPA (ab41684), rabbit anti- $\alpha$ smooth muscle actin ( $\alpha$-SMA) (ab5694), rabbit anti-vesicleassociated membrane protein (VAMP)2 (ab3374) antibodies, and the lactate dehydrogenase (LDH) assay kit were from Abcam. Rabbit anti-GAPDH (2118) and rabbit anti-phospho-myosin light chain (MLC) 2 antibodies Ser19 (3671) and Thr18/Ser19 (3674) were from Cell Signal Technology. (-)-Blebbistatin (S7099) and Y-27632 (S1049) were from Selleckchem. Jasplakinolide (420107) and cytochalasin D (250255) were from Merck Millipore. ML-7 (I2764) and superoxide dismutase (S5395) were from Sigma-Aldrich. Sulfosuccinimidyloleate (SSO; sc-208408) and horseradish peroxidase (HRP)-conjugated secondary antibodies (sc-2004, sc2005) were from Santa Cruz Biotechnology. ox-LDL (YB-002) was from Yiyuan Biotech.

\section{Animals and Tissue Harvest}

Eight-week-old specific pathogen-free male C57BL/6 and apo: ${ }^{-/-}$mice were obtained from Guangdong Medical Laboratory Animal Center and maintained within a temperature- and humidity-controlled environment on a 12-hour light/dark cycle. All experimental mice were housed and handled according to the Guide for the Care and Use of Laboratory Animals (NIH publication No.
1.0.0., revised 2011). All studies were conducted using procedures approved in advance by the Animal Ethics Committee of Sun YatSen University.

Mice were placed on a $0.15 \%$ cholesterol diet for 20 weeks before euthanasia. After anesthesia, aortas perfused with $4 \%$ formaldehyde were harvested for histological analysis.

\section{Culture of Primary RASMC and Treatment}

RASMC were from Sciencell (R6110) and maintained in DMEM (Gibco) with $10 \%$ fetal bovine serum (Gibco) and $1 \%$ penicillin-streptomycin (Gibco) at $37^{\circ} \mathrm{C}$ in a humidified incubator ( $5 \% \mathrm{CO}_{2} / 95 \%$ air), as described previously [11]. After $24 \mathrm{~h}$ of serum-free DMEM starvation, passages 4-8 RASMC at 70-80\% confluence were loaded with $20 \mu \mathrm{g} / \mathrm{ml}$ ox-LDL or DMEM for $24 \mathrm{~h}$. For signaling studies, cells were pre-exposed to $50 \mathrm{nmol} / \mathrm{l}$ jasplakinolide, $50 \mathrm{nmol} / \mathrm{l}$ cytochalasin D, $3 \mu \mathrm{mol} / \mathrm{l}$ Y27632, 1.25-10 $\mu \mathrm{mol} / \mathrm{l}$ blebbistatin, or 1.25-10 $\mu \mathrm{mol} / \mathrm{l} \mathrm{ML-7} \mathrm{for} 1 \mathrm{~h}$ and subsequently costimulated with $20 \mu \mathrm{g} / \mathrm{ml}$ ox-LDL for $24 \mathrm{~h}$. For the study of CD36 inhibitor, cells were sequentially treated with SSO $(2.5-20 \mu \mathrm{mol} / \mathrm{l})$ for 20 min, washed 3 times with Dulbecco's PBS, and incubated for $24 \mathrm{~h}$ in DMEM containing $20 \mu \mathrm{g} / \mathrm{ml}$ ox-LDL.

\section{Preparation of Conditioned Medium}

Conditioned medium (CM) from RASMC with or without treatment was prepared as described previously [11]. Briefly, the culture medium was collected and centrifuged for $10 \mathrm{~min}$ at $800 \mathrm{~g}$ to remove cell debris. The medium was concentrated 100 -fold using an Amicon Ultra centrifuge filter-3K (Merck Millipore) according to the instructions.

\section{Western Blotting}

RASMC were lysed with radioimmunoprecipitation assay buffer (CST) containing 1\% Halt ${ }^{\mathrm{TM}}$ protease and phosphatase inhibitor cocktail (Thermo Scientific) for total protein extraction. Total protein concentration of lysates was measured using a bicinchoninic acid protein kit (Pierce). Sodium dodecylsulfate-polyacrylamide gel (12\%) was loaded with lysates or CM. After electrophoresis, the proteins in the gel were blotted onto polyvinylidene difluoride membranes (Bio-Rad), and the membranes were subsequently blocked for $1 \mathrm{~h}$ at room temperature with $5 \% \mathrm{w} / \mathrm{v}$ bovine serum albumin in Tris-buffered saline supplemented with $0.1 \%$ Tween-20 (TBST). Membranes were incubated in primary antibodies (Thr18/Ser19 1:1,000, Ser19 1:1,000, rabbit anti-GAPDH $1: 1,000,1 \mu \mathrm{g} / \mathrm{ml}$ rabbit anti-VAMP2, $1 \mu \mathrm{g} / \mathrm{ml}$ rabbit anti-CyPA, and $1 \mu \mathrm{g} / \mathrm{ml}$ mouse anti-actin) overnight at $4^{\circ} \mathrm{C}$. After rinsing 3 times in TBST, HRP-conjugated secondary antibodies (goat antirabbit IgG-HRP 1:5,000 and goat anti-mouse IgG-HRP 1:2,000) were incubated for $1 \mathrm{~h}$ at room temperature. Proteins were visualized with an enhanced chemiluminescence detection system (Bio$\mathrm{Rad})$. Densitometry analysis was performed using ImageJ software (NIH).

\section{Immunohistochemistry}

Aortas were fixed, paraffin-embedded, sectioned, and immunostained as previously described [7]. In brief, after deparaffinization, rehydration, and antigen retrieval, sections were blocked in $10 \%$ goat serum. Sections were immunostained with primary antibodies (rabbit anti- $\alpha$-SMA antibody 1:200 and rabbit anti-CyPA antibody $1: 100$ ) overnight at $4^{\circ} \mathrm{C}$. Normal rabbit IgG acted as a negative control. After washing 3 times with TBST, slides were 
Fig. 1. There is abundant CyPA and $\alpha$-SMA expression in atherosclerotic plaque. Photomicrographs showing cross sections from the thoracic aorta stained with $\operatorname{HE}(\mathbf{a}$, b) and CyPA stain (c, d). e, f Immunohistochemical analysis of thoracic aorta stained with $\alpha$-SMA. Bars: $200 \mu \mathrm{m}$.
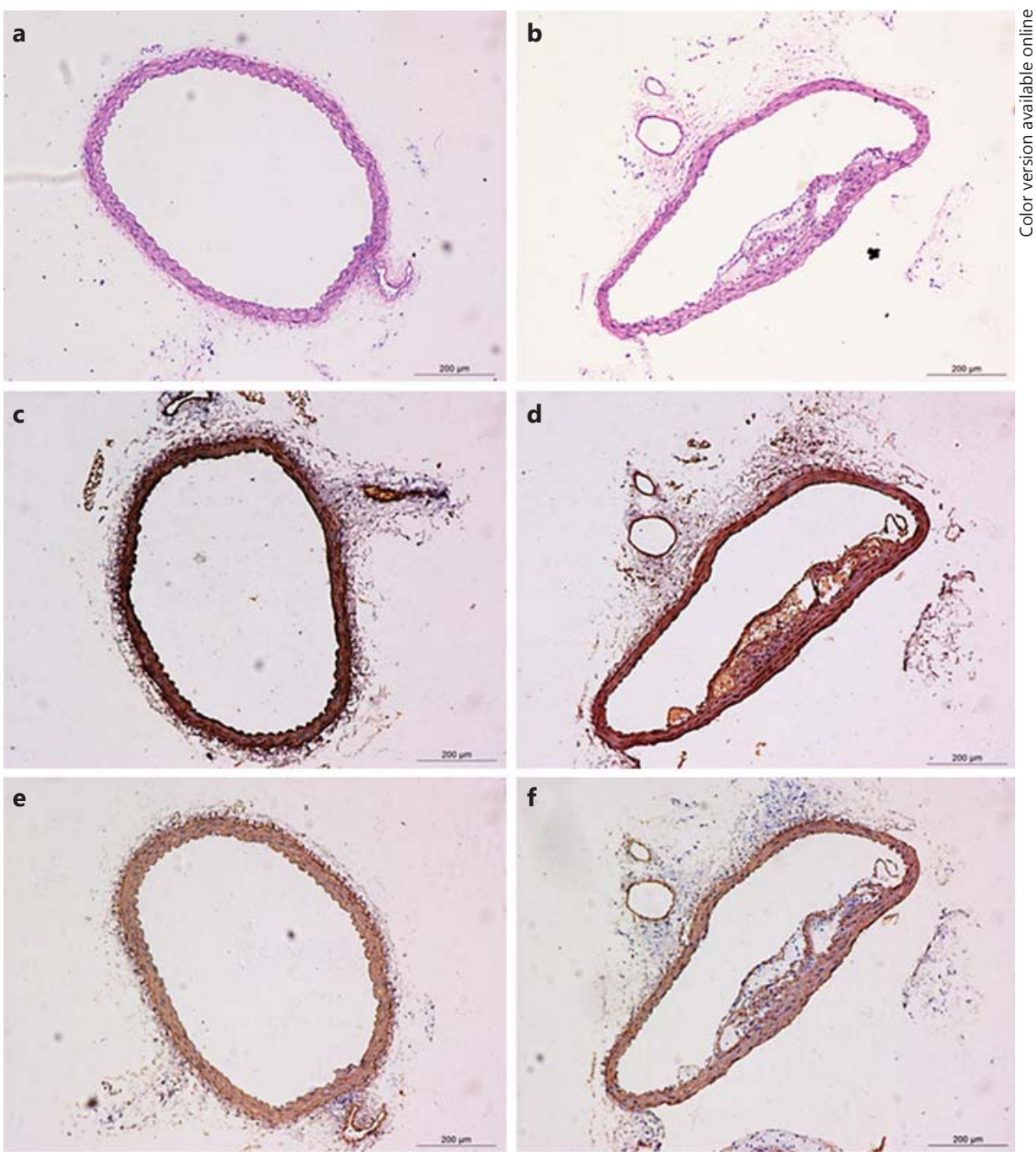

incubated in $0.3 \%$ hydrogen peroxide in Tris-buffered saline. Slides were incubated with goat poly-HRP conjugated secondary antibody (Dako). 3,3-diaminobenzidine was used to visualize positive staining. Finally, slides were counterstained with hematoxylin. The percentage of positive DAB staining was determined by Image-Pro Plus software (Media Cybernetics, Rockville, Md., USA).

\section{RNA Interference}

Stealth RNAi ${ }^{\mathrm{TM}}$ siRNA duplexes (sequences: siRNA \# 1, UCCUCAUCAUCAUCAUCGUUUACUU; siRNA \#2, AAGUAAACGAUGAUGAUGAUGAGGA) targeting rat VAMP2 mRNA (NM 012663.2) were designed and synthesized by Invitrogen. Stealth $\mathrm{RNAi}^{\mathrm{TM}}$ siRNA negative control LO GC (Invitrogen) acted as a nontargeting control. RASMC at 50\% confluence were transfected with $100 \mathrm{nmol} / \mathrm{l}$ of siRNA using Lipofectamine RNAiMAX (Invitrogen) for $48 \mathrm{~h}$. Cells were growth arrested by incubation in serum-free DMEM for $24 \mathrm{~h}$ followed by incubation with $20 \mu \mathrm{g} / \mathrm{ml}$ ox-LDL for $24 \mathrm{~h}$. Cells were lysed, and the culture medium was collected for experiments.

\section{Statistical Analysis}

Data are presented as mean \pm SEM. Normally distributed data were analyzed using Student's t test, one-way ANOVA and then the LSD post hoc test. Statistical analyses were performed with SPSS v16.0 (IBM, USA). Statistical significance was accepted at $\mathrm{p}<0.05$.

\section{Results}

\section{Abundant Expression of CyPA and $\alpha-S M A$ Are} Present in Atherosclerotic Plaque

After 20 weeks on a high cholesterol diet, aortic atherosclerotic lesions in the apoE $\mathrm{E}^{-/-}$mice were confirmed by hematoxylin-eosin ( $\mathrm{HE}$ ) staining (fig. 1a, b). The expression of CyPA (fig. 1c, d) and a-SMA (fig. 1e, f) increased (1.48-fold and 1.54-fold, respectively) in aortas 

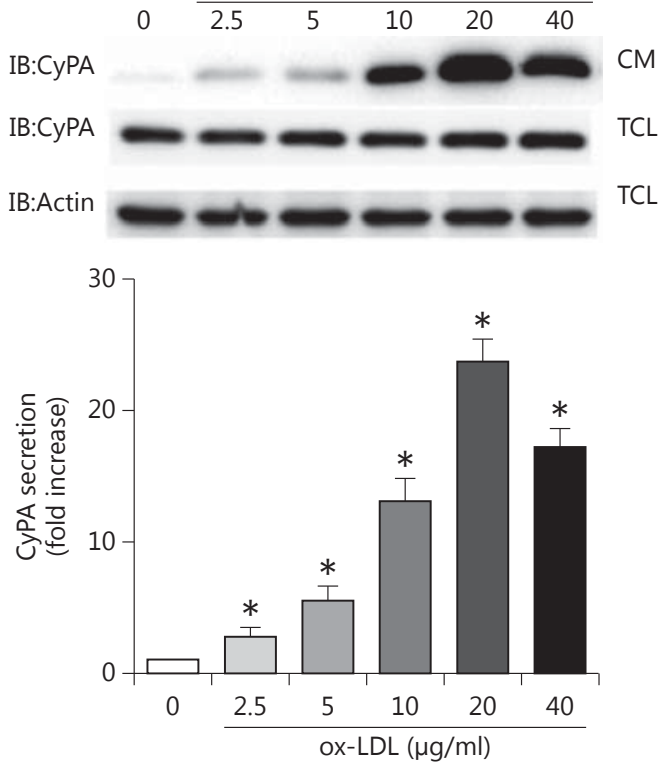
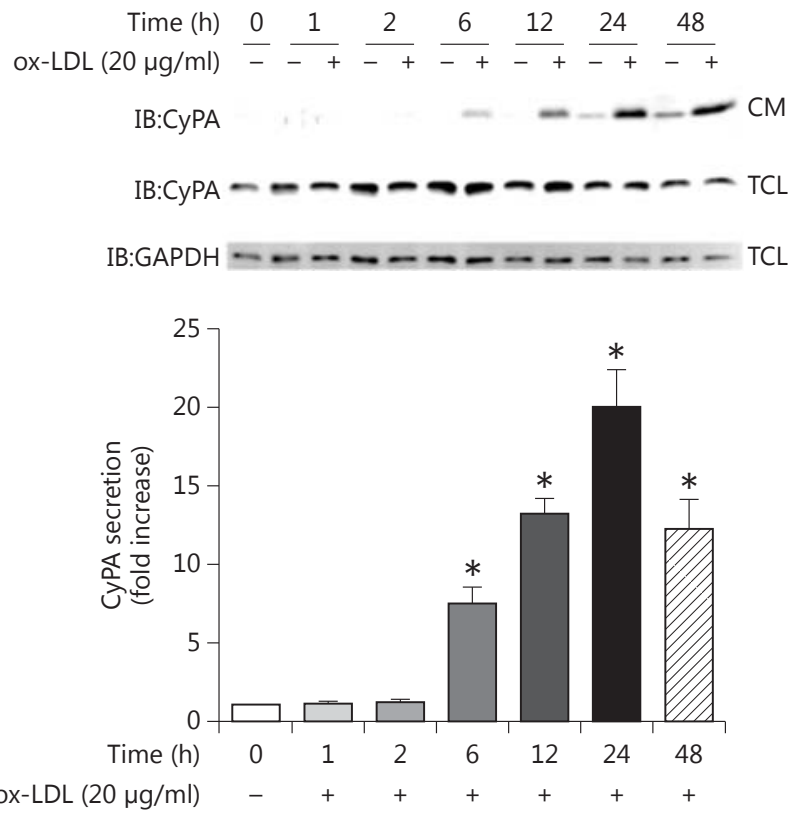

b
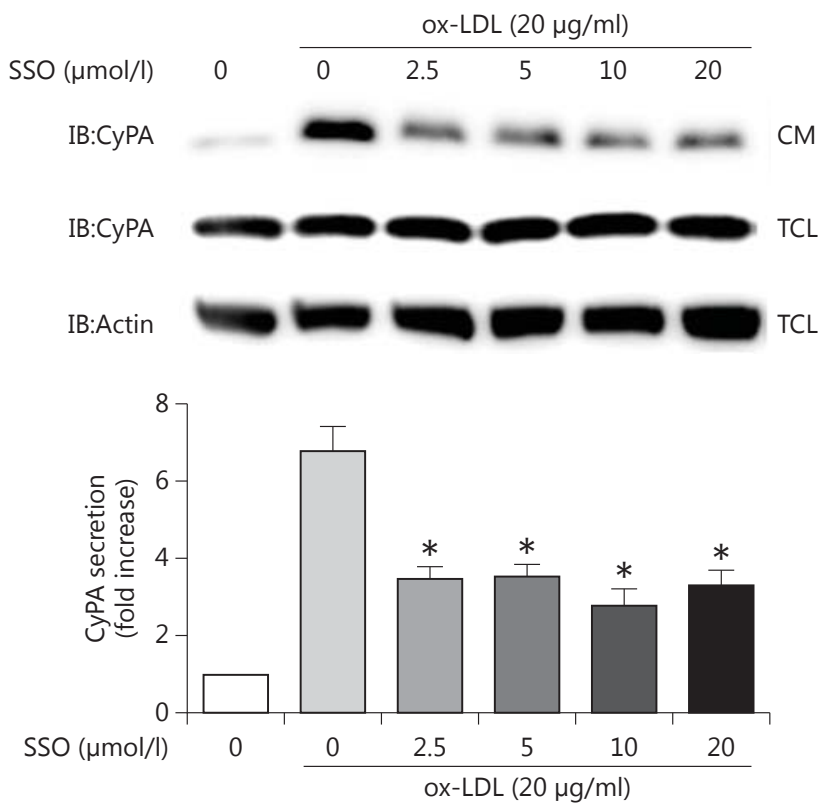

Fig. 2. ox-LDL-induced dose- and time-dependent CyPA secretion is dependent on CD36. a Densitometric quantification and representative Western blot of total cell lysate (TCL) and CM from RASMC incubated with ox-LDL $(2.5-40 \mu \mathrm{g} / \mathrm{ml})$ for $24 \mathrm{~h}$ and from RASMC stimulated with ox-LDL $(20 \mu \mathrm{g} / \mathrm{ml})$ for the indicated times. b Densitometric quantification and representative Western blot of TCL and CM from RASMC preincubated with SSO (2.5-20 $\mu \mathrm{mol} / \mathrm{l})$ for $20 \mathrm{~min}$ before exposure to $20 \mu \mathrm{g} / \mathrm{ml}$ ox-LDL for $24 \mathrm{~h}$. Results are presented as mean \pm SEM of 3 independent experiments performed in triplicate. ${ }^{*} \mathrm{p}<0.05$ compared with control (a) or ox-LDL alone (b). 


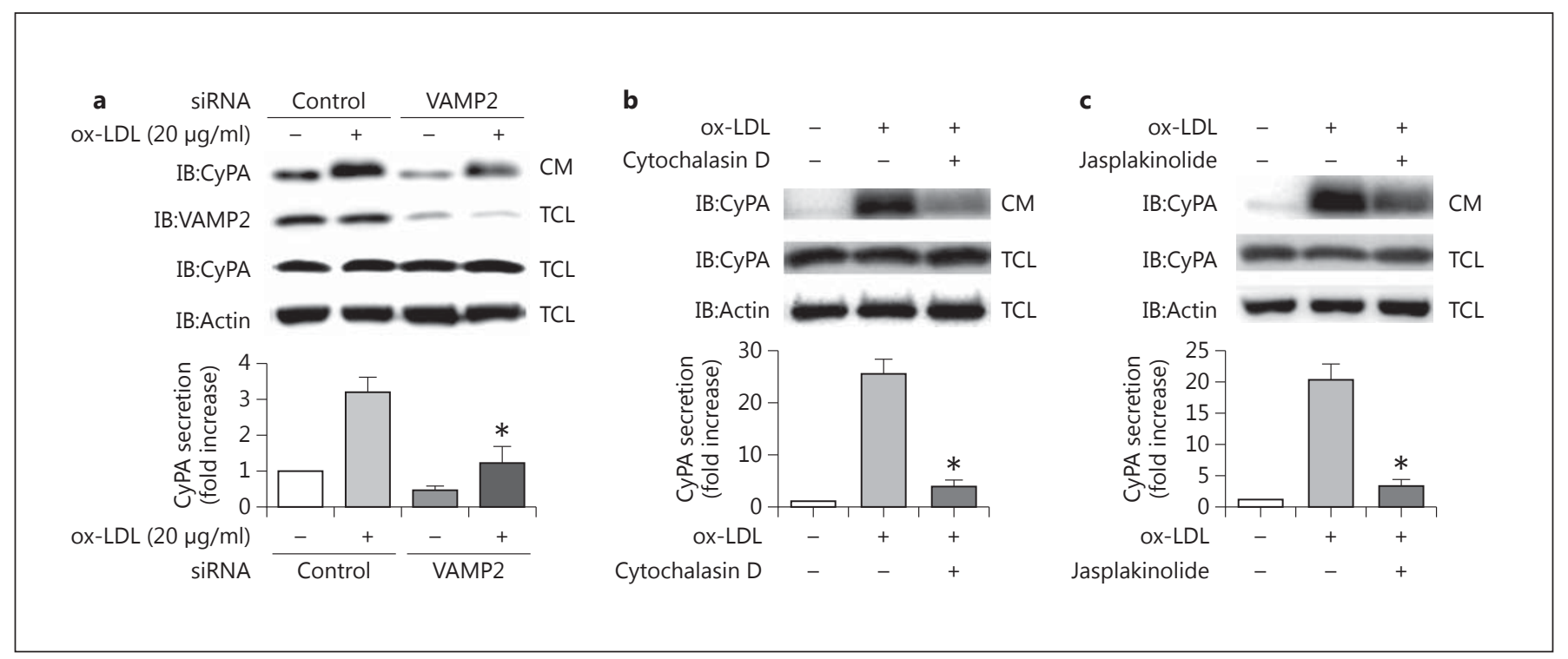

Fig. 3. ox-LDL-induced CyPA secretion requires vesicle transportation and actin remodeling. a Densitometric quantification and representative Western blot of total cell lysate (TCL) and CM from RASMC transfected with VAMP2 siRNA before incubation with $20 \mu \mathrm{g} / \mathrm{ml}$ ox-LDL for $24 \mathrm{~h}$. b Densitometric quantification and representative Western blot of TCL and CM from RASMC pretreated with the actin depolymerizing agent cytochalasin $\mathrm{D}(50 \mathrm{nmol} / \mathrm{l})$ for
$1 \mathrm{~h}$ before exposure to $20 \mu \mathrm{g} / \mathrm{ml}$ ox-LDL for $24 \mathrm{~h}$. c Densitometric quantification and representative Western blot of TCL and CM from RASMC pretreated with the actin-polymerizing agent jasplakinolide $(50 \mathrm{nmol} / \mathrm{l})$ for $1 \mathrm{~h}$ before exposure to $20 \mu \mathrm{g} / \mathrm{ml}$ ox-LDL for $24 \mathrm{~h}$. Results are presented as mean \pm SEM of 3 independent experiments performed in triplicate. ${ }^{*} \mathrm{p}<0.05$ compared with siRNA control (a) or ox-LDL alone $(\mathbf{b}, \mathbf{c})$. with atherosclerotic plaque from apoE $\mathrm{E}^{-/-}$mice compared with wild-type mice. These data indicate that increased CyPA levels might be an important mediator involved in VSMC proliferation in atherosclerotic lesions.

\section{ox-LDL Induces Secretion of CyPA from RASMC by}

CD36

CyPA can be secreted from RASMC in response to the ROS inducer LY83583 [11, 12]. ox-LDL induces ROS in VSMC [8-10]. Therefore, we examined whether oxLDL would induce CyPA secretion by Western blot analysis of CM. Incubation of RASMC with different concentrations of ox-LDL $(2.5-40 \mu \mathrm{g} / \mathrm{ml})$ for $24 \mathrm{~h}$ caused a dose-dependent increase in CyPA secretion, with the maximal increase observed at $20 \mu \mathrm{g} / \mathrm{ml}$ (fig. 2a). CyPA secretion was initiated following $6 \mathrm{~h}$ of stimulation of RASMC with $20 \mu \mathrm{g} / \mathrm{ml}$ ox-LDL, with abundant secretion at $24 \mathrm{~h}$ (fig. 2b). The increase of CyPA secretion in the $\mathrm{CM}$ was not associated with an increase in the levels of $\mathrm{LDH}$, thereby excluding the possibility that the exocytosis of CyPA was due to cell damage (online suppl.fig.S1;www.karger.com/doi/10.1159/000449387).
However, the intracellular CyPA protein level did not change significantly in RASMC with or without ox-LDL stimulation (fig. 2a, b).

CD36, a key receptor for ox-LDL, mediates ox-LDL uptake [13-15] and ox-LDL-specific ROS production [10] in VSMC. We further explored the role of CD36 as a potential receptor mediating the $\mathrm{CyPA}$ secretion induced by ox-LDL. Secretion of CyPA induced by ox-LDL was significantly decreased in RASMC pretreated with the CD36 inhibitor SSO (2.5-20 $\mu \mathrm{mol} / \mathrm{l}$; fig. 2c). These results demonstrate that CD36 may be involved in the secretion of CyPA induced by ox-LDL.

Fig. 4. ox-LDL causes phosphorylation of MLC and ox-LDL-induced CyPA secretion is dependent on MLC phosphorylation. a Densitometric quantification and representative immunoblot of total cell lysate (TCL) from RASMC treated with ox-LDL (2.5-40 $\mu \mathrm{g} / \mathrm{ml}$ ) for $24 \mathrm{~h}$. b Densitometric quantification and representative immunoblot of TCL and CM from RASMC preincubated with blebbistatin $(1.25-10 \mu \mathrm{mol} / \mathrm{l})$ for $1 \mathrm{~h}$ before exposure to $20 \mu \mathrm{g} / \mathrm{ml}$ ox-LDL for $24 \mathrm{~h}$. Results are presented as mean \pm SEM of 3 independent experiments performed in triplicate. ${ }^{*} \mathrm{p}<0.05$ compared with control (a) or ox-LDL (b) alone.

(For figure see next page.) 
a

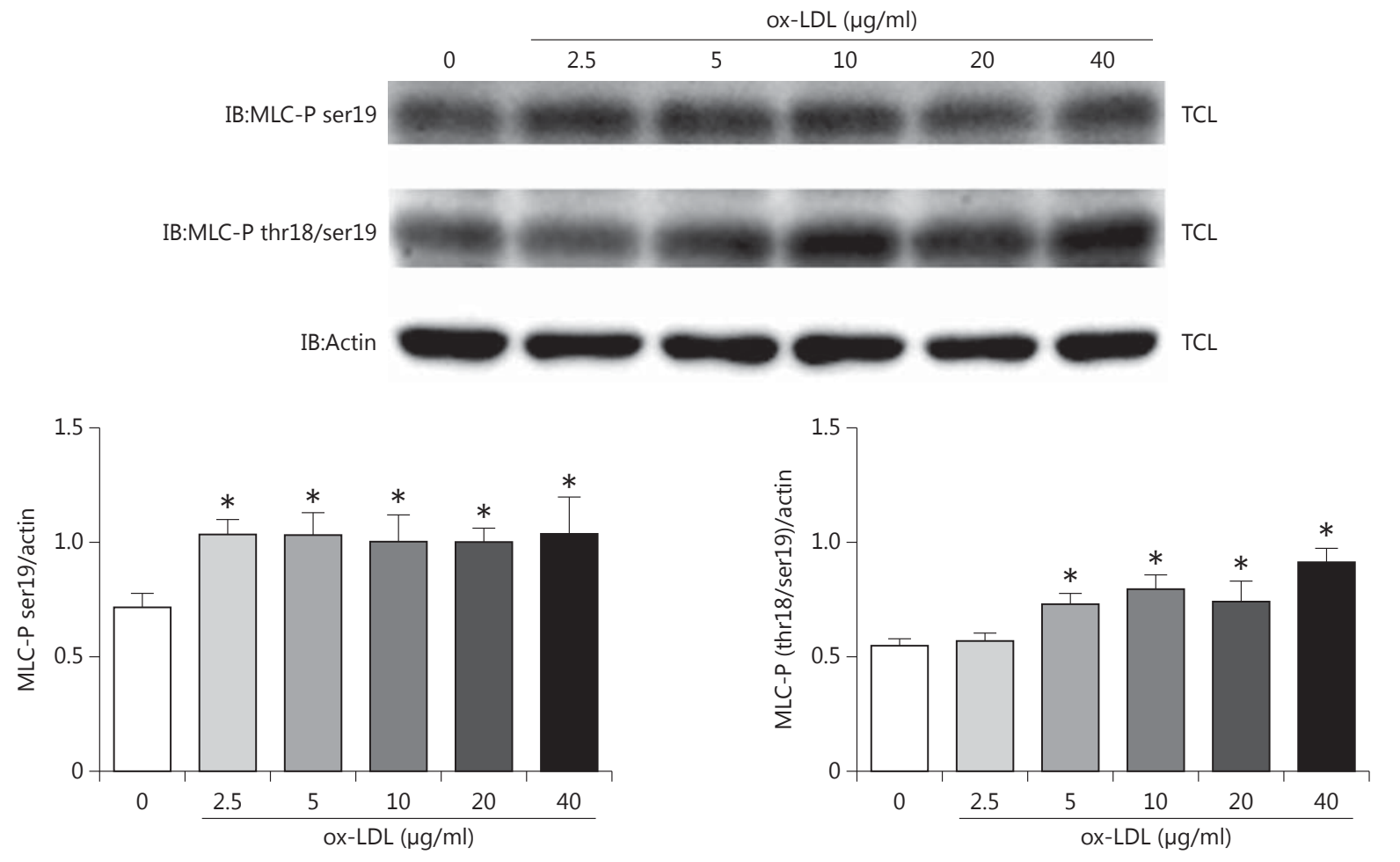

b

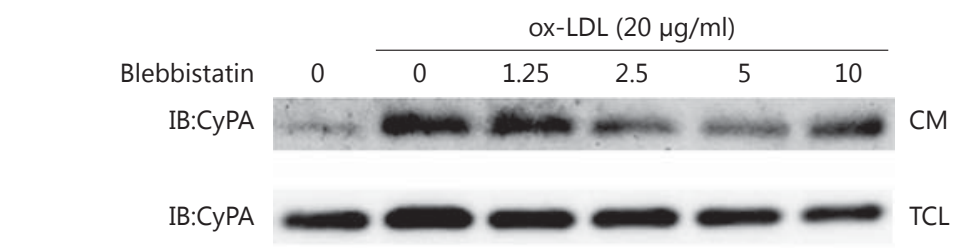

IB:MLC-P ser19

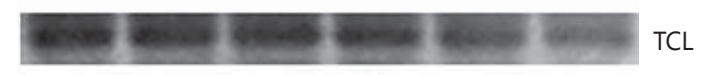

IB:MLC-P thr18/ser19

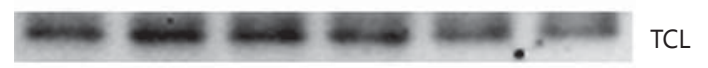

IB:Actin
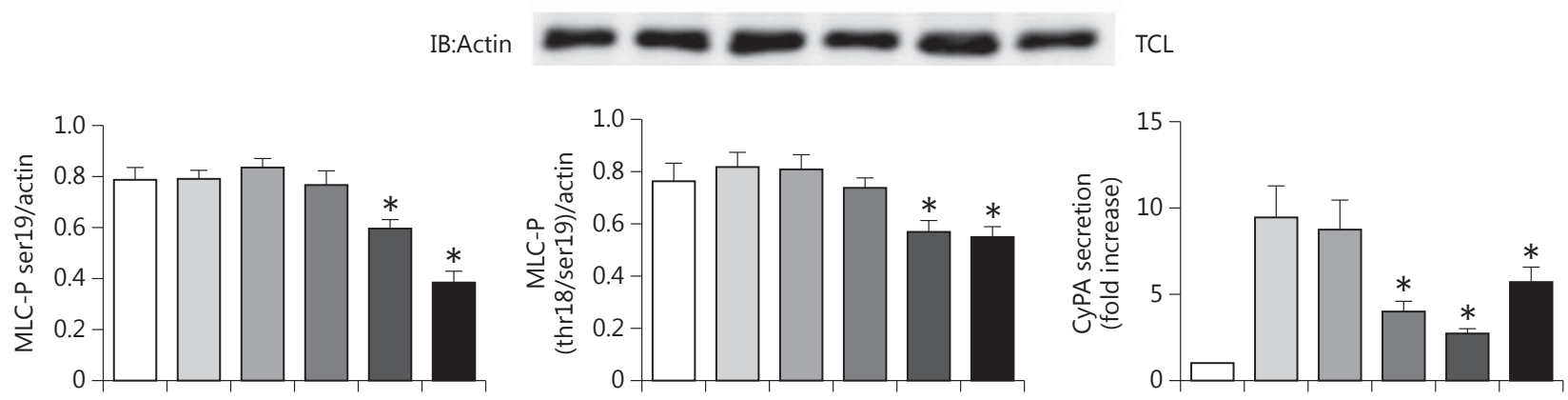

Blebbistatin

\begin{tabular}{lllll}
0 & 1.25 & 2.5 & 5 & 10 \\
\hline ox-LDL $(20 \mu \mathrm{g} / \mathrm{ml})$
\end{tabular}

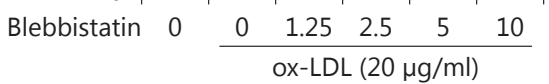

\begin{tabular}{clccccc} 
Blebbistatin 0 & 0 & 1.25 & 2.5 & 5 & 10 \\
\cline { 3 - 4 } & & &
\end{tabular} 
CyPA Secretion Induced by ox-LDL Requires Vesicle

Transportation and Actin Remodeling

Actin cytoskeleton and vesicle transportation are involved in the exocytosis of CyPA induced by LY83583 [11]. VAMP2 has been shown to play a key role in the secretion of synaptic vesicles $[16,17]$. Compared with control siRNA, VAMP2 siRNA partially inhibited oxLDL-induced CyPA secretion (fig. 3a). Besides, ox-LDLinduced CyPA secretion was significantly reduced by either the actin-depolymerizing agent cytochalasin D (50 $\mathrm{nmol} / \mathrm{l}$; fig. $3 \mathrm{~b}$ ) or the actin-polymerizing agent jasplakinolide (50 nmol/l; fig. $3 \mathrm{c}$ ). These findings suggest that vesicle transportation and actin remodeling may be involved in ox-LDL-induced CyPA secretion.

$C y P A$ Secretion Induced by ox-LDL Requires

Phosphorylation of MLC

Phosphorylation of MLC mediates actin remodeling [18] and vesicle trafficking [19]. ox-LDL has been reported to drive phosphorylation of MLC in vitro [20,21]. Concomitant with increased CyPA secretion, monophosphorylation at Ser19 and diphosphorylation at Ser 19 and Thr18 of MLC were induced by exposure to ox-LDL $(2.5-40 \mu \mathrm{g} / \mathrm{ml})$ in RASMC for $24 \mathrm{~h}$ (fig. $4 \mathrm{a})$. Furthermore, pre-exposure to the MLC inhibitor blebbistatin $(1.25-10 \mu \mathrm{mol} / \mathrm{l})$ not only reduced phosphorylation of MLC, but also significantly inhibited exocytosis of CyPA (fig. 4b). These results suggest that CyPA secretion induced by ox-LDL is mediated by phosphorylation of MLC.

\section{CyPA Secretion Induced by ox-LDL Is Partially}

Dependent on Diphosphorylation of MLC

Monophosphorylation at Ser19 and diphosphorylation at Ser19 and Thr18 of MLC are mainly regulated by the calcium-dependent MLCK pathway and the rhoassociated coiled-coil kinase (ROCK)-dependent pathway, respectively $[22,23]$. To further delineate the pathway initiated by ox-LDL contributing to $\mathrm{CyPA}$ secretion, we assessed these 2 pathways using ROCK inhibitor Y27632 and MLCK inhibitor ML-7. ML-7 (1.25-10 $\mu \mathrm{mol} / \mathrm{l})$ reduced monophosphorylation at Ser 19 of MLC and increased CyPA secretion induced by ox-LDL significantly (fig. 5a). Y27632 (3 $\mu \mathrm{mol} / \mathrm{l})$ suppressed diphosphorylation at Ser19 and Thr18 of MLC and blunted CyPA secretion induced by ox-LDL (fig. 5b). These data demonstrate that the ROCK pathway is important for ROCK-dependent diphosphorylation MLC and mediates the CyPA secretion induced by ox-LDL.

\section{Discussion}

In this study, we showed that abundant expression of $\mathrm{CyPA}$ and $\alpha$-SMA are present in atherosclerotic lesions. In the in vitro study, we demonstrated that ox-LDL-induced CyPA secretion requires vesicle transportation, actin remodeling, and ROCK-dependent diphosphorylation of MLC. In addition, we found that CyPA induced by ox-LDL is dependent on CD36 activity. Our data suggest that ox-LDL-induced VSMC-derived CyPA secretion may be associated with strong expression of $\mathrm{CyPA}$ in atherosclerotic lesions.

CyPA exhibits a wide array of pathophysiological properties, including the induction of inflammatory cell chemotaxis $[24,25]$, the proliferation of $\operatorname{VSMC}[7,12]$, and the secretion of matrix metalloproteinases $[2,4]$. A previous study showed that CyPA is abundantly expressed in atherosclerotic plaque [4]. Similarly, we found that abundant expressions of CyPA and $\alpha$-SMA are present in atherosclerotic lesions from apoE ${ }^{-/-}$mice. Either gene deletion of CyPA or shRNA-based knockdown of $\mathrm{CyPA}$ in $\mathrm{apoE}^{-/-}$mice alleviates the development of AS $[1,6]$. All of this evidence indicates that CyPA acts as a proatherogenic factor in the development of AS.

The source of CyPA present in atherosclerotic plaque remains unclear. Previous studies have demonstrated that VSMC-derived CyPA exerts significant effects on vascular remodeling $[2,7]$. CyPA can be secreted from RASMC in response to the ROS inducer LY83583 [11, 12]. ox-LDL, as a proatherogenic factor, induces intracellular production of ROS in various cell types such as VSMC [8-10] and macrophages [26-28]. It has been reported that ox-LDL induces CyPA secretion from THP-1 via an unknown mechanism [29]. In our study, we found that ox-LDL induces CyPA secretion from RASMC. CD36, a receptor for ox-LDL that is present on various

Fig. 5. ox-LDL-induced CyPA secretion is dependent on the diphosphorylation of MLC mediated by the ROCK pathway but not on the monophosphorylation of MLC mediated by the MLCK pathway. a Densitometric quantification and representative Western blot of total cell lysate (TCL) and CM from RASMC pretreated with the MLCK inhibitor ML-7 (1.25-10 $\mu \mathrm{mol} / \mathrm{l})$ for $1 \mathrm{~h}$ before exposure to $20 \mu \mathrm{g} / \mathrm{ml}$ ox-LDL for $24 \mathrm{~h}$. b Densitometric quantification and representative Western blot of TCL and CM from RASMC pretreated with ROCK inhibitor Y27632 (3 $\mathrm{mol} / \mathrm{l})$ for $1 \mathrm{~h}$ before exposure to $20 \mu \mathrm{g} / \mathrm{ml}$ ox-LDL for $24 \mathrm{~h}$. Results are presented as mean \pm SEM of 3 independent experiments performed in triplicate. ${ }^{*} \mathrm{p}<0.05$ compared with ox-LDL alone.

(For figure see next page.) 
a
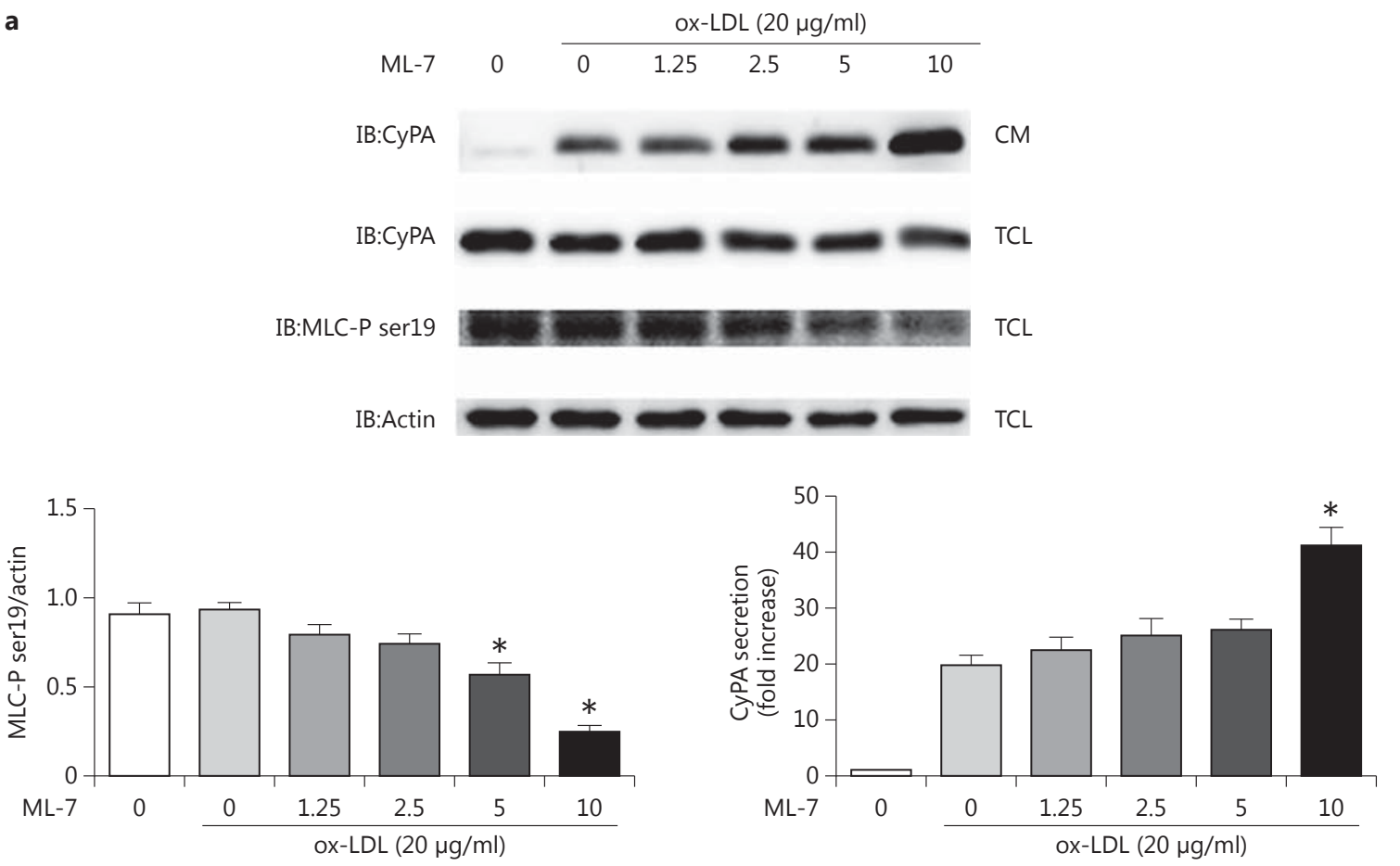

b
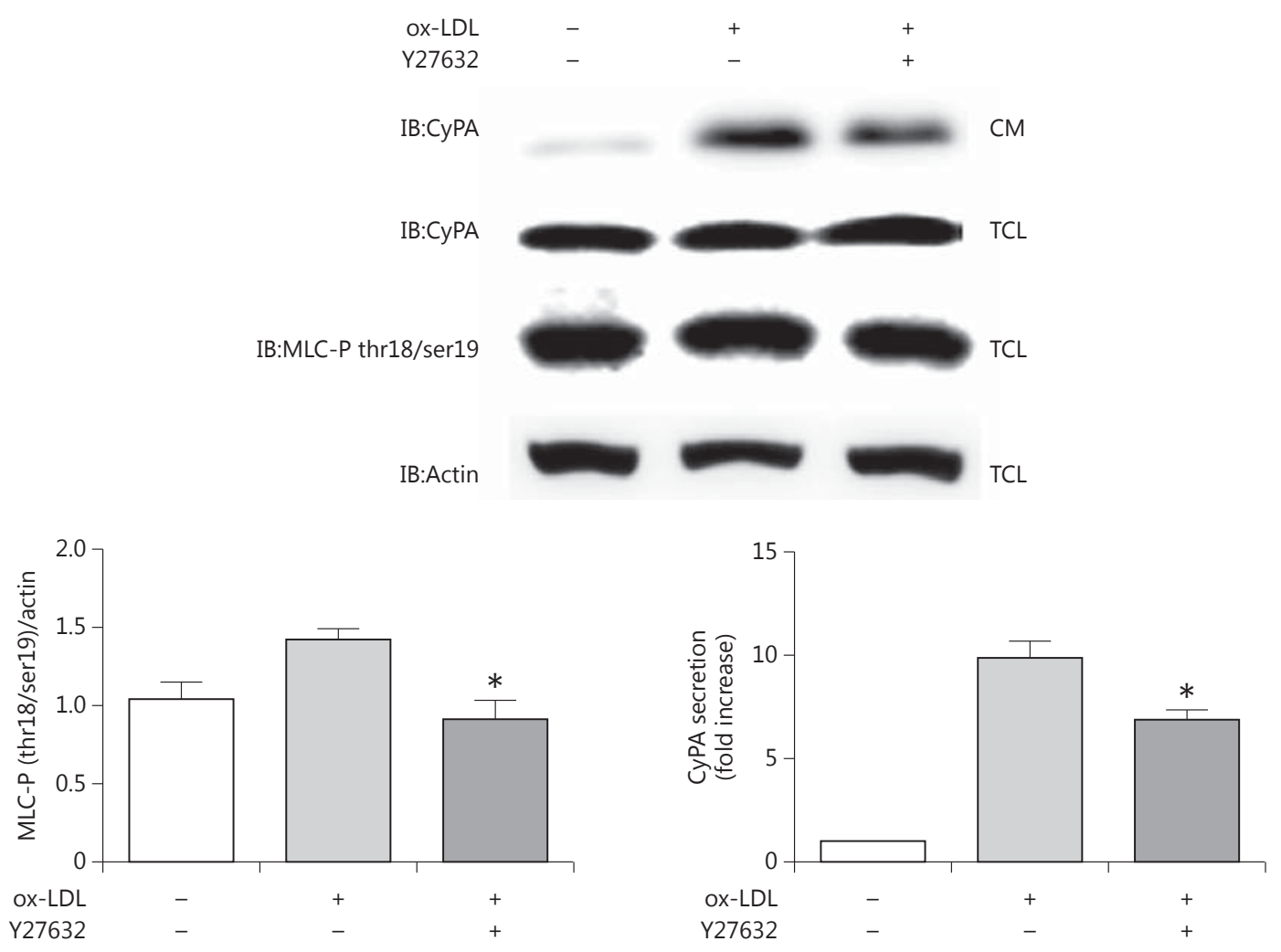
types of cells, plays a significant role in atherogenic processes through interaction with ox-LDL. CD36 modulates ox-LDL-specific ROS production in VSMC [10]. We also found that the CD36 inhibitor SSO reverses CyPA secretion induced by ox-LDL. These observations suggest that CyPA secretion induced by ox-LDL is dependent on CD36 and that ox-LDL-induced VSMC-derived CyPA secretion could be an important source of the CyPA that is present in atherosclerotic plaque.

Soluble $\mathrm{N}$-ethylmaleimide-sensitive factor attachment protein receptors (SNAREs), a superfamily of small proteins, are involved in the membrane fusion events [30], intracellular protein trafficking, and secretory processes. VAMP2, a member of the SNARE family, is implicated in ROS-induced exocytosis of CyPA [11]. Similarly, we found that RNA interference of VAMP2 reduces oxLDL-induced exocytosis of CyPA. Actin remodeling mediates vesicular trafficking pathways [31,32]. A previous study demonstrated that either actin-polymerizing or actin-depolymerizing agents inhibit ROS-induced exocytosis of CyPA [11]. Likewise, we found that ox-LDL-induced CyPA secretion is dependent on the regulated disassembly and reorganization of the actin cytoskeleton. These results demonstrate the involvement of vesicle transportation and actin remodeling in VSMC-derived CyPA secretion.

Phosphorylation of MLC facilitates vesicle transportation $[19,33]$. In our study, we found that ox-LDL induces both the monophosphorylation and diphosphorylation of MLC in RASMC. In addition, we found that the MLC inhibitor blebbistatin reverses the phosphorylation of MLC and CyPA secretion induced by ox-LDL. Consistent with our results, it has been reported that blebbistatin abolishes the CyPA secretion induced by LY83583 [11]. These findings indicate that MLC phosphorylation plays a vital role in RASMC-derived CyPA secretion.

In VSMC, monophosphorylation and diphosphorylation of MCL are mainly mediated by the MLCK-dependent pathway [22] and the ROCK-dependent pathway [23], respectively. A previous study reported that the selective ROCK inhibitor Y27632 significantly inhibits ROS-induced CyPA secretion, but the role of MLCK in ROS-induced CyPA secretion was not observed [11]. In our study, we investigated the role of MLCK and ROCK in the phosphorylation of MLC and the secretion of CyPA induced by ox-LDL, and found that CyPA secretion induced by ox-LDL is partially dependent on the diphosphorylation of MLC mediated by ROCK but not on the monophosphorylation of MLC mediated by MLCK. Our findings demonstrate that ox-LDL-induced CyPA secretion requires diphosphorylation of MLC mediated by ROCK.

\section{Conclusions}

In conclusion, this study provides evidence that VSMC-derived CyPA induced by ox-LDL may be associated with the strong expression of CyPA in atherosclerotic lesions. Furthermore, we found that knockdown of VAMP2 and actin-polymerizing or actin-depolymerizing agent inhibited ox-LDL-induced CyPA secretion, suggesting that this secretion requires vesicle transportation and actin remodeling. Finally, we demonstrated that diphosphorylation of MLC at Ser19 and Thr18 and ox-LDL-induced CyPA secretion are both linked with ox-LDL-induced CyPA secretion, and that the ROCK pathway is especially important for the diphosphorylation of MLC and mediates CyPA secretion induced by ox-LDL.

\section{Acknowledgments}

This study was supported by the National Science Foundation of China (grant No. 81570213, 91439125, 81270212, 81670364), the National Science Foundation for Young Scientists of China (grant No. 81000101), the Natural Science Foundation of Guangdong Province (grant No. S2012010009663, 2016A030313356), the Fundamental Research Funds for the Central Universities of China (grant No. 10ykpy20), the Medical Scientific Research Foundation of Guangdong Province (grant No. A2015044), and a Yat-Sen Scholarship for Young Scientists, Sun Yat-Sen Memorial Hospital, Sun Yat-Sen University, China (to S.X.).

\section{Disclosure Statement}

The authors have no conflicts of interest to declare.
References

\footnotetext{
1 Nigro P, Satoh K, O'Dell MR, Soe NN, Cui Z, Mohan A, Abe J, Alexis JD, Sparks JD, Berk BC: Cyclophilin A is an inflammatory mediator that promotes atherosclerosis in apolipoprotein E-deficient mice. J Exp Med 2011;208: 53-66.

2 Satoh K, Nigro P, Matoba T, O’Dell MR, Cui Z, Shi X, Mohan A, Yan C, Abe J, Illig KA, Berk BC: Cyclophilin A enhances vascular oxidative stress and the development of angiotensin II-induced aortic aneurysms. Nat Med 2009;15:649-656.
} 
3 Seizer P, Ochmann C, Schönberger T, Zach S, Rose M, Borst O, Klingel K, Kandolf R, MacDonald HR, Nowak RA, Engelhardt S, Lang F, Gawaz M, May AE: Disrupting the EMMPRIN (CD147)-cyclophilin A interaction reduces infarct size and preserves systolic function after myocardial ischemia and reperfusion. Arterioscler Thromb Vasc Biol 2011;31:13771386.

4 Seizer P, Schönberger T, Schött M, Lang MR, Langer HF, Bigalke B, Krämer BF, Borst O, Daub K, Heidenreich O, Schmidt R, Lindemann S, Herouy Y, Gawaz M, May AE: EMMPRIN and its ligand cyclophilin A regulate MT1-MMP, MMP-9 and M-CSF during foam cell formation. Atherosclerosis 2010; 209:51-57.

5 Satoh K, Fukumoto Y, Sugimura K, Miura Y, Aoki T, Nochioka K, Tatebe S, MiyamichiYamamoto S, Shimizu T, Osaki S, Takagi Y, Tsuburaya R, Ito Y, Matsumoto Y, Nakayama M, Takeda M, Takahashi J, Ito K, Yasuda S, Shimokawa H: Plasma cyclophilin A is a novel biomarker for coronary artery disease. Circ J 2013;77:447-455.

6 Yan J, Li Y, Wang C, Wang Z, Yuan W: Regression of atherosclerotic plaques after lentivirus-mediated RNA interference of cyclophilin $\mathrm{A}$ in $\mathrm{ApoE}^{-/-}$mice. Int J Cardiol 2013;169:e87-e90.

7 Satoh K, Matoba T, Suzuki J, O’Dell MR, Nigro P, Cui Z, Mohan A, Pan S, Li L, Jin ZG, Yan C, Abe J, Berk BC: Cyclophilin A mediates vascular remodeling by promoting inflammation and vascular smooth muscle cell proliferation. Circulation 2008;117:30883098.

8 Larroque-Cardoso P, Swiader A, Ingueneau C, Negre-Salvayre A, Elbaz M, Reyland ME, Salvayre R, Vindis C: Role of protein kinase C delta in ER stress and apoptosis induced by oxidized LDL in human vascular smooth muscle cells. Cell Death Dis 2013;4:e520.

9 Hsieh CC, Yen MH, Yen CH, Lau YT: Oxidized low density lipoprotein induces apoptosis via generation of reactive oxygen species in vascular smooth muscle cells. Cardiovasc Res 2001;49:135-145

10 Sukhanov S, Higashi Y, Shai SY, Itabe H, Ono K, Parthasarathy S, Delafontaine P: Novel effect of oxidized low-density lipoprotein: cellular ATP depletion via downregulation of glyceraldehyde-3-phosphate dehydrogenase. Circ Res 2006;99:191-200.

11 Suzuki J, Jin ZG, Meoli DF, Matoba T, Berk $\mathrm{BC}$ : Cyclophilin A is secreted by a vesicular pathway in vascular smooth muscle cells. Circ Res 2006;98:811-817.
12 Jin ZG, Melaragno MG, Liao DF, Yan C, Haendeler J, Suh YA, Lambeth JD, Berk BC: Cyclophilin A is a secreted growth factor induced by oxidative stress. Circ Res 2000;87: 789-796.

13 Xue JH, Yuan Z, Wu Y, Liu Y, Zhao Y, Zhang WP, Tian YL, Liu WM, Liu Y, Kishimoto C: High glucose promotes intracellular lipid accumulation in vascular smooth muscle cells by impairing cholesterol influx and efflux balance. Cardiovasc Res 2010;86:141-150.

14 Zingg JM, Ricciarelli R, Andorno E, Azzi A: Novel 5' exon of scavenger receptor CD36 is expressed in cultured human vascular smooth muscle cells and atherosclerotic plaques. Arterioscler Thromb Vasc Biol 2002;22:412417.

15 Ricciarelli R, Zingg JM, Azzi A: Vitamin E reduces the uptake of oxidized LDL by inhibiting CD36 scavenger receptor expression in cultured aortic smooth muscle cells. Circulation 2000;102:82-87.

16 Karpova AY, Tervo DG, Gray NW, Svoboda $\mathrm{K}$ : Rapid and reversible chemical inactivation of synaptic transmission in genetically targeted neurons. Neuron 2005;48:727-735.

17 Tojima T, Akiyama H, Itofusa R, Li Y, Katayama H, Miyawaki A, Kamiguchi H: Attractive axon guidance involves asymmetric membrane transport and exocytosis in the growth cone. Nat Neurosci 2007;10:58-66.

18 Konstantinidis G, Moustakas A, Stournaras C: Regulation of myosin light chain function by BMP signaling controls actin cytoskeleton remodeling. Cell Physiol Biochem 2011;28: 1031-1044.

19 Neco P, Giner D, Viniegra S, Borges R, Villarroel A, Gutierrez LM: New roles of myosin II during vesicle transport and fusion in chromaffin cells. J Biol Chem 2004;279:2745027457.

20 Wraith KS, Magwenzi S, Aburima A, Wen Y, Leake D, Naseem KM: Oxidized low-density lipoproteins induce rapid platelet activation and shape change through tyrosine kinase and Rho kinase-signaling pathways. Blood 2013;122:580-589.

21 Essler M, Retzer M, Bauer M, Heemskerk JW, Aepfelbacher M, Siess W: Mildly oxidized low density lipoprotein induces contraction of human endothelial cells through activation of Rho/Rho kinase and inhibition of myosin light chain phosphatase. J Biol Chem 1999; 274:30361-30364.

22 Allen BG, Walsh MP: The biochemical basis of the regulation of smooth-muscle contraction. Trends Biochem Sci 1994;19:362-368.

23 Woodsome TP, Polzin A, Kitazawa K, Eto M, Kitazawa T: Agonist- and depolarization-induced signals for myosin light chain phosphorylation and force generation of cultured vascular smooth muscle cells. J Cell Sci 2006; 119:1769-1780.
24 Seizer P, Klingel K, Sauter M, Westermann D, Ochmann C, Schönberger T, Schleicher R, Stellos K, Schmidt EM, Borst O, Bigalke B, Kandolf R, Langer H, Gawaz M, May AE: Cyclophilin A affects inflammation, virus elimination and myocardial fibrosis in Coxsackievirus B3-induced myocarditis. J Mol Cell Cardiol 2012;53:6-14.

25 Song F, Zhang X, Ren XB, Zhu P, Xu J, Wang L, Li YF, Zhong N, Ru Q, Zhang DW, Jiang JL, Xia B, Chen ZN: Cyclophilin A (CyPA) induces chemotaxis independent of its peptidylprolyl cis-trans isomerase activity: direct binding between $\mathrm{CyPA}$ and the ectodomain of CD147. J Biol Chem 2011;286:8197-8203.

26 Bae YS, Lee JH, Choi SH, Kim S, Almazan F, Witztum JL, Miller YI: Macrophages generate reactive oxygen species in response to minimally oxidized low-density lipoprotein: tolllike receptor 4- and spleen tyrosine kinasedependent activation of NADPH oxidase 2. Circ Res 2009;104:210-218, 21p-218p.

27 Lee CF, Qiao M, Schröder K, Zhao Q, Asmis $\mathrm{R}$ : Nox4 is a novel inducible source of reactive oxygen species in monocytes and macrophages and mediates oxidized low density lipoprotein-induced macrophage death. Circ Res 2010;106:1489-1497.

28 Choi SH, Gonen A, Diehl CJ, Kim J, Almazan F, Witztum JL, Miller YI: SYK regulates macrophage MHC-II expression via activation of autophagy in response to oxidized LDL. Autophagy 2015;11:785-795.

29 Fach EM, Garulacan LA, Gao J, Xiao Q, Storm SM, Dubaquie YP, Hefta SA, Opiteck GJ: In vitro biomarker discovery for atherosclerosis by proteomics. Mol Cell Proteomics 2004;3: $1200-1210$

30 Shi L, Shen QT, Kiel A, Wang J, Wang HW, Melia TJ, Rothman JE, Pincet F: SNARE proteins: one to fuse and three to keep the nascent fusion pore open. Science 2012;335:13551359.

31 Johnson JL, Monfregola J, Napolitano G, Kiosses WB, Catz SD: Vesicular trafficking through cortical actin during exocytosis is regulated by the Rab27a effector JFC1/Slp1 and the RhoA-GTPase-activating protein Gem-interacting protein. Mol Biol Cell 2012; 23:1902-1916.

32 Eitzen G: Actin remodeling to facilitate membrane fusion. Biochim Biophys Acta 2003; 1641:175-181.

33 Wollert T, DePina AS, DeSelm CJ, Langford GM: Rho-kinase is required for myosin-IImediated vesicle transport during $\mathrm{M}$-phase in extracts of clam oocytes. Biol Bull 2003;205: 195-197.
The Role of ox-LDL in Cyclophilin A Secretion
J Vasc Res 2016;53:206-215

DOI: 10.1159/000449387 